\title{
Recombinant Protein Galectin-1 Exposure to 0M-1 Cell Proliferation: An Experimental In Vitro Study
}

\author{
Andra Rizqiawan, Indra Mulyawan, Aries Muharram, Ni Putu Mira Sumarta, David B. Kamadjaja, Coen P. Danudiningrat \\ Department of Oral and Maxillofacial Surgery, Faculty of Dental Medicine, Universitas Airlangga, Surabaya, Indonesia
}

\section{Abstract}

\begin{abstract}
Aim: The aim of this study was to overcome the shortage of galectin-1 (Gal-1) protein and to determine cell proliferation by adding recombinant protein that has a high protein content of the squamous cell OM-1. Materials and Methods: A presented study was Experimental laboratory study. The role of recombinant protein galectin-1 (r-Gal-1) in combating squamous cell carcinoma of the OM-1, as compared to HOC313 squamous cell carcinoma without exposure to r-Gal-1, through the promotion of cell proliferation. An in vitro experiment was conducted on the following three groups: a negative control group using OM-1 cells, an intervention group comprising OM-1 cells to which $8 \mu \mathrm{g} / \mathrm{mL}$ r-Gal-1 was added, and a positive control incorporating HOC 313 cells that were highly invasive. The proliferation level of the cells was measured by means of the optical density on a microplate reader on days $0,1,2,3$, and 4. In the three test groups, an increased proliferation rate was obtained on days 1, 2, 3, and 4 on OM-1, OM-1 + r-Gal-1, and HOC313. The statistical analysis was carried out using analysis of variance test, Kruskal-Wallis test, least significant difference test, and Mann-Whitney test. Results: The proliferation rate increased significantly $(P<0.05)$ in the treatment group $(\mathrm{OM}-1+\mathrm{r}-\mathrm{Gal}-1)$ as compared to the negative control group (OM-1). The positive control group (HOC313) experienced the highest degree of proliferation among the three groups. Conclusion: Gal-1 is a protein that plays a key role in the processes of cancer metastasis and invasion.
\end{abstract}

Keywords: OM-1, Optical Density, Oral Squamous Cell Carcinoma, Proliferation, Recombinant Protein Galectin-1

Received: 21-07-2019, Revised: 01-11-2019, Accepted: 28-11-2019, Published: 02-06-2020

\section{INTRODUCTION}

Cancer, whose global incidence is increasing due to lifestyle changes, ranks the second most common cause of death following cardiovascular diseases and affects all levels of society. Oral cancer ranks as the sixth leading type cancer globally and accounts for more than $90 \%$ of squamous cell carcinoma. ${ }^{[1]}$ The factors responsible for this type of oral cancer can be either intrinsic or extrinsic. The intrinsic factors comprise general malnutrition or anemia due to iron deficiency, whereas the extrinsic factors comprise smoking, alcohol, chewing betel nut, and genotype infection by the human papillomavirus (HPV). Diets low in fresh fruit and vegetables have recently been found as risk factors for an individual developing squamous cell carcinoma. ${ }^{[2]}$

Cancers originating in the epithelial tissue are referred to as carcinomas. Squamous cell carcinoma, a malignant tumor derived from epithelium tissue with cell structure group, is

\begin{tabular}{|l|l|}
\hline \multicolumn{2}{|c|}{ Access this article online } \\
\hline Quick Response Code: & Website: \\
\hline & www.jioh.org \\
\hline & \\
\hline
\end{tabular}

able to spread throughout the body via the bloodstream and lymphatic system. Squamous cell carcinoma is the most common form of malignancy affecting the oral cavity at approximately $90 \%-95 \%$ of malignant neoplasms of the oral cavity. It is usually located on the tongue ventral and lateral, lips, mouth floor, buccal mucosa, and retromolar regions. ${ }^{[3]}$ Squamous cell carcinoma of the oral cavity remains a significant cause of death worldwide with approximately 500,000 new cases being diagnosed annually. ${ }^{[4]}$

In 2011, it was estimated that more than 11,460 deaths resulted from head and neck squamous cell carcinoma in

\section{Address for correspondence: Dr. Andra Rizqiawan, Department of Oral and Maxillofacial Surgery, \\ Faculty of Dental Medicine, Universitas Airlangga, JI. Prof. Dr. Moestopo 47, Surabaya 60132, Indonesia. E-mail: andra-r@fkg.unair.ac.id}

This is an open access journal, and articles are distributed under the terms of the Creative Commons Attribution-NonCommercial-ShareAlike 4.0 License, which allows others to remix, tweak, and build upon the work non-commercially, as long as appropriate credit is given and the new creations are licensed under the identical terms.

For reprints contact: reprints@medknow.com

How to cite this article: Rizqiawan A, Mulyawan I, Muharram A, Sumarta NP, Kamadjaja DB, Danudiningrat CP. Recombinant protein galectin-1 exposure to OM-1 cell proliferation: An experimental in vitro study. J Int Oral Health 2020;12:270-4. 
the United States and over 300,000 deaths globally. The majority of the patients presented stage III/IV head and neck squamous cell carcinoma and only approximately $40 \%$ of the patients received a prognosis of survival beyond 5 years. Individuals afflicted with squamous cell carcinoma metastases of the head and neck generally had a survival rate of less than $10 \%{ }^{[5]}$

Epithelial mesenchymal transition (EMT) is a biological process characterized by a reversible increase in cell migration and invasion, changes in the cytoskeleton, and resistance to apoptosis. Kalluri and Weinberg ${ }^{[6]}$ state that the classification of EMT occurring in cancer cases to be one of Type 3. Type-2 EMT is associated with the regeneration of tissue and organ fibrosis, and Type-1 EMT is associated with embryogenesis and organ development. A recent study reported that in a primary tumor such as squamous cell carcinoma of the head and neck the symptoms include low E-cadherin EMT, high vimentin, and morphological changes. ${ }^{[7]}$

In a microarray-based analysis, by comparing a cell with the type of EMT and squamous cell carcinoma with epithelial type as many as 63 genes playing a role in rendering cancer cells more malignant were identified ${ }^{[8,9]}$ One of the 63 genes is galectin-1 (Gal-1). Kim et al. ${ }^{[10]}$ found in their research that Gal-1 can be used as a symptom of squamous cell carcinoma of the oral cavity. They further said that the higher the expression of Gal1 , the more serious will be the prognosis for the cancer. Strik et al. ${ }^{[1]}$ argued that Gal-1 can increase the rate of proliferation in human glioma cells.

The galectin family of lectins is involved in the $\beta$-galactoside-binding protein comprising approximately 130 amino acids found in the carbohydrate recognition domain (CRD). Galectin is found in the cell nucleus, cytoplasm, and extracellular material of all cell types. The physiology and pathology of the role of galectin in cell growth involves embryogenesis, inflammation, migration, deployment processes, and apoptosis. ${ }^{[12]}$ To date, galectin has been identified in as many as 15 species of mammal. Gal-1 is expressed in a variety of both normal and pathological tissues with various functions ${ }^{[13]}$ and, together with its ligand, represents an important regulator of the immune response as it is able to modulate the process of homeostasis, immune abnormalities of $\mathrm{T}$ cells, inflammation, and allergies.

Preliminary in vitro studies conducted by researchers to establish the level of Gal-1 expression in the two cell types are squamous cell carcinoma of the OM-1 and HOC 313 , the result ingredient protein expression of Gal-1 levels were lower in the OM-1 cells compared to expression protein Gal-1 on cells HOC313 so it cannot as a guide to the level of invasion and cell proliferation ability. ${ }^{[14]}$ To overcome these difficulties, recombinant proteins that have a highprotein content of the squamous cell carcinoma OM-1 were added to prove that the protein appears to trigger the level of invasion and cell proliferation.

In the results of previous studies on squamous cell carcinoma exposed OM-1 recombinant protein galectin-1 (r-Gal-1) with a concentration $8 \mu \mathrm{g} \mathrm{mL}$ with a 24-h observation time increased cell migration, but the observation the rate of cell proliferation has not been proven. Therefore, it should be investigated whether the concentration with long observations over $0,1,2,3$, and 4 days can increase the proliferation of squamous cell carcinoma of the OM-1. ${ }^{[5,14]}$

Based on the foregoing background, need to be analyzed with in vitro studies to prove the role of r-Gal-1 with a concentration $8 \mu \mathrm{g} / \mathrm{mL}$ against squamous cell carcinoma of the OM-1 compared to squamous cell carcinoma HOC313 without being exposed to r-Gal-1 in enhancing cell proliferation.

\section{Materials and Methods}

\section{Study design}

This study used a Experimental Laboratory study conducted between June and July 2013 at the laboratory of the Department of Oral and Maxillofacial Surgery, Graduate School and Institute of Biomedical and Health Sciences, Hiroshima University, Japan.

\section{Sampling criteria}

This study used a 450-nm absorbance BioRad machine (Biorad, California, USA). The inclusion criteria of the study were HOC313 and OM-1 cells that were passaged three times, r-Gal-1, and MTT assay. The exclusion criteria of the study wereHOC313 and OM-1 cells that were passaged more than three times. HOC 313 and OM-1 cells were stabilized and characterized according to previous studies. The MTT assay method was in accordance with the data sheet of the Cell Counting Kit-8 (CCK-8; Dojindo Molecular Technologies, Rockville, USA.). In this study, there was no bias.

\section{Experimental analysis}

Human oral OM-1 and HOC313 cells were obtained from the laboratory of the Department of Oral and Maxillofacial Surgery, Faculty of Dentistry, Hiroshima University, Japan. These cells were maintained in Dulbecco's Modified Eagle Medium (DMEM; Sigma, St. Louis, Missouri) supplemented with $10 \%$ fetal bovine serum (Biowest, Nuaillé, France), $100 \mu \mathrm{g} / \mathrm{mL}$ streptomycin, and 100 units $/ \mathrm{mL}$ penicillin (Invitrogen Corporation, Carlsbad, California).

OM-1 and HOC 313 cells were taken $1 \mathrm{~mL}$ of the stock, then do thawing process and in the culture medium in $10 \mathrm{~mL}$ of DMEM $+10 \%$ fetal bovine $+1 \%$ penicillinstreptomycin. The medium was placed on a $10-\mathrm{cm}$ Petri plate and incubated at a temperature of $37^{\circ} \mathrm{C}$ in $5 \% \mathrm{CO}_{2}$ 
for $24 \mathrm{~h}$. The cells were cultured until an $80 \%$ confluent monolayer was formed. OM-1 and HOC313 cells were resuspended in phosphate buffer saline (PBS) and $0.25 \%$ trypsin and inserted into 96-well microplate of 5000 cells per well with DMEM medium $+10 \%$ fetal bovine serum $+1 \%$ penicillin-streptomycin.

Cell proliferation was measured using a commercial CCK-8 according to manufacturer's instructions. The samples were divided into the following three groups:

- Group 1: OM-1 cells.

- Group 2: OM-1 + r-Gal-1 cells $(8 \mu \mathrm{g} / \mathrm{mL})$.

- Group 3: HOC313 cells.

Each well comprised 5000 cells and 100-mL DMEM + $10 \%$ FBS $+1 \%$ penicillin-streptomycin and incubated at a temperature of $37^{\circ} \mathrm{C}$ for $0,1,2,3$, and 4 days. Cells were counted using the Invitrogen Countess Automated Cell Counter (Invitrogen, California, USA). After incubation, $10 \mathrm{~mL}$ of CCK-8 solution (Dojindo Molecular Technologies) was added to each well and cells were further incubated for $2 \mathrm{~h}$. Absorbance at $450 \mathrm{~nm}$ was measured using a microplate reader and the relative cell viability was calculated.

\section{Statistical analysis}

Statistical analysis was performed using Statistical Package for the Social Sciences software, version 16.0 (IBM, NewYork, USA). The comparative analysis of biomaterials was conducted using a two-way analysis of variance (ANOVA) followed by a Kolmogorov-Smirnov normality test and an equality of variances test. Specific analysis was performed using an ANOVA test followed by a Kolmogorov-Smirnov normality test and an equality of variances test. A time period analysis was performed using a Kruskal-Wallis test, whereas an intergroup analysis was performed using the least significant difference (LSD) and Mann-Whitney tests. A value $P<0.05$ was considered statistically significant [Table 1].

\section{RESULTS}

Cell viability was measured by using CCK-8 and a microplate reader at a wavelength of $50 \mathrm{~nm}$. The optical density (OD) measurements obtained are shown in Table 1. Table 1 shows the results of OD on days $0,1,2,3$, and 4. An increase in the level of OD was interpreted by an increase in cell proliferation. The mean OD count of OM-1 cell proliferation increased from days 1 to 4 . In OM-1 +
r-Gal-1 cells, an increase in proliferation that began on days $1-4$, the OD value higher than the OM-1. At 313 HOC, cell proliferation increased from days 1 to 4 . At 313 HOC, cell proliferation achieved the highest degree of proliferation as compared to OM-1 and OM-1 + r-Gal-1 cells from days 1 to 4 .

Based on the images above [Figure 1], it can be explained that the OD measurements using a microplate reader an increase in cell proliferation OM-1 after the administration r-Gal- 1 on days $0,1,2,3$, and 4 . Cell proliferation achieved the highest degree of proliferation on day 4 as compared to days 1,2 , and 3 .

According to the one-way ANOVA result [Table 2], the treatment between groups had a significant difference on days 2 and $3(P<0.05)$. On the basis of the results of the Kruskal-Wallis test, there was a significant difference on days 0,1 , and $4(P<0.05)$. Furthermore, in order to identify a group with a significant difference, both LSD and Mann-Whitney tests were administered. These showed no significant difference on day 0. However, on days 1,2, 3, and 4 a significant difference was noted between the groups.

\section{Discussion}

Cancer is a disease characterized by the disruption of, or failure of, the multiplication regulatory mechanisms in a multicellular organism resulting in uncontrolled changes in cell behavior. Such changes are caused by genetic transformations, particularly in growth-regulating genes, namely, proto-oncogene and tumor suppressor genes. Cells undergoing continuous transformation proliferate but do not differentiate a fact that suppresses the growth of normal cells. High cell proliferation and uncontrolled nature due to the interruption of balance factors, proto-oncogenes and tumor suppressor genes, result in

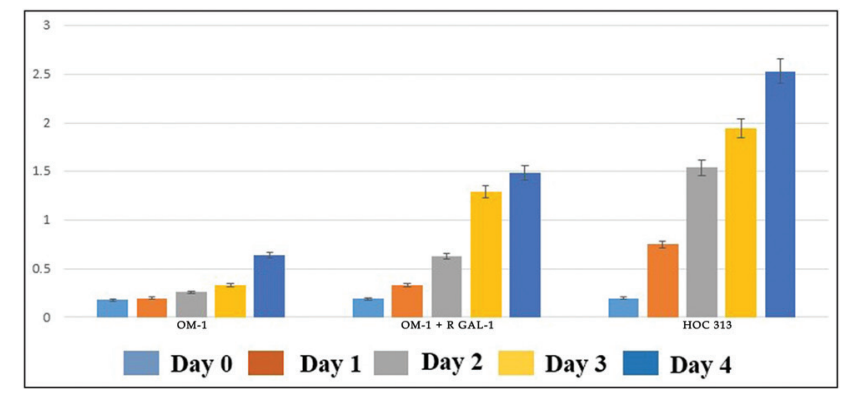

Figure 1: The optical density measurements

\begin{tabular}{|c|c|c|c|c|c|}
\hline Day sample & Day 0 & Day 1 & Day 2 & Day 3 & Day 4 \\
\hline & $x \pm \mathrm{SB}$ & $x \pm \mathrm{SB}$ & $x \pm \mathrm{SB}$ & $x \pm \mathrm{SB}$ & $x \pm \mathrm{SB}$ \\
\hline OM-1 & $0.18 \pm 0.0064$ & $0.20 \pm 0.0027$ & $0.26 \pm 0.0131$ & $0.33 \pm 0.029$ & $0.64 \pm 0.0133$ \\
\hline OM-1 + r Gal-1 & $0.19 \pm 0.01$ & $0.33 \pm 0,0065$ & $0.63 \pm 0.016$ & $1.29 \pm 0.031$ & $1.49 \pm 0.090$ \\
\hline HOC 313 & $0.20 \pm 0.014$ & $0.75 \pm 0.033$ & $1.54 \pm 0.086$ & $1.94 \pm 0.212$ & $2.53 \pm 0.225$ \\
\hline
\end{tabular}


Rizqiawan, et al.: Recombinant galectin-1 to cell proliferation

\begin{tabular}{|c|c|c|c|c|c|}
\hline Day sample & Day 0 & Day 1 & Day 2 & Day 3 & Day 4 \\
\hline \multicolumn{6}{|l|}{ OM-1 } \\
\hline $\mathrm{OM}-1+\mathrm{r}-\mathrm{Ga}$ & & & & & \\
\hline HOC 313 & - & - & $0.000^{*}$ & $0.000^{*}$ & - \\
\hline
\end{tabular}

*Significant

increased production of growth factors and the number of cell surface receptors that can trigger intracellular signal transduction of transcription factors to increase production. $\cdot^{[2,4]}$

In the cell cycle, lasting an orderly process of cell growth and decrease to duplicated genetic information from one cell generation to the next generation of cells. During the process of running, the DNA must be properly duplicated and the copy of the chromosome must be precise. DNA damage causes cessation of the cell cycle at the G1 phase and the subsequent occurrence of a repair process. If damage to the DNA cannot be repaired, these cells will undergo apoptosis. Cell proliferation is an increase in the number of cells whose processes involve the cell cycle. ${ }^{[15]}$ Galectin is a carbohydrate-binding protein belonging to a group of proteins that contribute to various activities related to the biology of cancer, including tumor transformation, cell xcaks regulation, apoptosis, cell adhesion, proliferation, migration, and inflammation. Numerous studies contend that Gal-1 is involved in the biological activity in the head and neck squamous cell carcinoma. ${ }^{[16]}$

Tumor biology and clinical oncology experts say that Gal-1 is a potential therapeutic target against cancer. ${ }^{[7]}$ Gal-1 expression has been reported in different types of tumors, including astrocytoma, melanoma and prostrate, thyroid, colon, bladder, and ovarian carcinoma. ${ }^{[5]}$ Gal-1 is not differentially expressed in oral squamous papilloma and oral squamous cell carcinoma. ${ }^{[17]}$ From immunocytochemical and immunohistochemical Gal-1 in OSCC show high correlation whether morphological changes, in reactive or neoplastic cells. ${ }^{[18]}$ In gingival squamous cell carcinoma, Gal-1 plays an important role in immune escape and useful clinicopathological prognostic marker. ${ }^{[19]}$ Intracellular Gal-1 can enhance tumor cell proliferation and transformation by means of proteinprotein interactions with oncogenic RAS or with nuclear protein, GEMIN4, which is induced into RNA splicing. The role of Gal-1 in cell signaling involves activation of mitogen that enables the proliferation of active kinase (MAPK). Extracellular Gal-1 forms a multivalent bond with a variety of glycoproteins and glycolipids on the cell surface, as well as the extracellular matrix components such as fibronectin and laminin, activate intracellular signaling pathways that modulate cell proliferation and promote EMT. ${ }^{[20]}$

This study used OM-1 cells that are epithelial, low invasive, and express E-cadherin as a sign of adhesion between cells. HOC313 cells are mesenchymal shaped, highinvasive, and do not express E-cadherin so that there will be no adhesion between cells but express vimentin as one sign of an EMT. ${ }^{\left[{ }^{[9]}\right.}$ According to Rizqiawan et al.,$^{[14]}$ the expression of Gal-1 protein levels in OM-1 cells is lower than that in HOC 313 cells. This can be explained that the OM-1 is a cancer cell that has low capacity than HOC313 cell invasion. ${ }^{[14]}$ The study used the addition of Gal-1 protein using r-Gal-1 production Peprotech as much as 8 $\mu \mathrm{g} / \mathrm{mL}$ on OM-1 and cell proliferation rate measured from day $0,1,2,3$ and 4. Cell HOC313 is as a positive control.

Research has confirmed an increase in the proliferation rate after administration of $\mathrm{r}$-Gal- 1 on OM- 1 cells at a concentration of $8 \mu \mathrm{g} / \mathrm{mL}$ on days $1,2,3$, and 4 . Watersoluable tetrazolium results by using CCK-8. Figure 1 shows the OD measurements. Gal-1 can interact with HRas membrane, and intracellular Gal-1 can stabilize the interaction of HRas-GTP with the cell membrane, which then triggers a cascade comprising Raf kinase and extracellular-signal-regulated kinase (ERK). Another study also mentioned that there is a direct interaction between Gal-1 and HRas cells and SKOV3ip1 Hey (ovarian cancer) cell. ${ }^{[14]} \mathrm{c}-J u n$, a transcription factor, has been associated with the process of cell proliferation, tumor cell survival, and apoptosis. Many human tumors show elevated expression levels of c-Jun, and c-Jun activation could be an important factor for transformation and tumorigenesis. c-Jun protein is activated by phosphorylation cascade that requires activation of MEK-ERK and c-Jun N-terminal kinase (JNK). This study proves that, with the addition of recombinant protein, Gal-1can increase cell proliferation in the OM-1. Increased proliferation is caused by the activation of HRas, which is then followed by phosphorylation of c-Jun and JNK. ${ }^{[14]}$

Fischer et al ${ }^{[16]}$ showed that the antiproliferative potency of Gal-1 in a number of carcinoma cells requires a functional interaction with integrin $\alpha 5 \beta 1$. The antiproliferative effect is the result of inhibition of the Ras pathway-MEK-ERK, which, in turn, induces the transcription of p27 whose promoter contains two sites of $\mathrm{Sp}-1$, which can bind to Gal-1. Because of cascade inhibition of Ras-MEKERK by Gal-1, it increases Sp-1 transactivation and DNA binding due to reduced threonine phosphorylation of Sp-1. In addition, Gal-1 induces the transcription of p21 and p27 proteins selectively increases stability, whereas Gal-1 mediates the accumulation of p27 and 
Rizqiawan, et al.: Recombinant galectin-1 to cell proliferation

p21 to inhibit the activity of cyclin-dependent kinase 2, which ultimately results in the dismissal of G1 cell cycle and growth inhibition. ${ }^{[15]}$ The administration of r-Gal-1 can enhance the collective cell invasion and migration by increasing the expression of integrin $\alpha 2 .^{[14]}$ Transfected Gal-1 in squamous cell carcinoma can increase the expressions of MMP-9 and MMP-2, and increase the number of filopodia in cells. ${ }^{[16]}$

On termination of the study, the authors concluded that the addition of recombinant protein gal-1 OM-1 cell proliferation can improve between days 1 and 4 as compared to the control group. It can also be concluded that Gal-1 is one of the proteins that plays a role in the process of cancer metastasis and invasion. The study recommends further research to find out more about the role of Gal-1 in invasion process oral squamous cell carcinoma related with EMT.

\section{Data availability statement}

Available on request from Andra Rizqiawan (andra-r@, fkg.unair.ac.id).

\section{Acknowledgement}

We express our gratitude to Faculty of Dentistry, Hiroshima University, Japan, and Faculty of Dental Medicine, Universitas Airlangga, Indonesia, for their invaluable support for the research.

\section{Financial support and sponsorship}

Nil.

\section{Conflicts of interest}

There are no conflicts of interest.

\section{References}

1. Lemmer J, Feller L. Oral squamous cell carcinoma: Epidemiology, clinical presentation and treatment. J Cancer Ther 2012;3:263-8.

2. Prihantono P. Adjuvants therapy in oral cancer. Int J Surg Med 2018;4:183-7.

3. Sreejyothi HK, Rai H, Shreedevi B, Harikrishnan HK. Role of human papilloma virus in oral squamous cell carcinoma: Review article. Int J Contemp Med Res 2017;4:383-6.
4. Neville BW, Damm DD, Allen CM, Bouquot JE. Oral and Maxillofacial Pathology. 2nd ed. Philadelphia, PA: W.B. Saunders; 2002. p. 356-67.

5. Bartolazzi A. Galectins in cancer and translational medicine: From bench to bedside. Int J Mol Sci 2018;19:2934.

6. Kalluri R, Weinberg RA. The basics of epithelial-mesenchymal transition. J Clin Invest 2009;119:1420-8.

7. Rabinovich GA. Galectin-1 as a potential cancer target. Br J Cancer 2005;92:1188-92.

8. Higashikawa K, Yoneda S, Taki M, Shigeishi H, Ono S, Tobiume K, et al. Gene expression profiling to identify genes associated with high-invasiveness in human squamous cell carcinoma with epithelialto-mesenchymal transition. Cancer Lett 2008;264:256-64.

9. Higashikawa K, Yoneda S, Tobiume K, Saitoh M, Taki M, Mitani Y, et al. Deltanp63alpha-dependent expression of Id-3 distinctively suppresses the invasiveness of human squamous cell carcinoma. Int J Cancer 2009;124:2837-44.

10. Kim HJ, Do IG, Jeon HK, Cho YJ, Park YA, Choi JJ, et al. Galectin 1 expression is associated with tumor invasion and metastasis in stage IB to IIA cervical cancer. Hum Pathol 2013;44:62-8.

11. Strik MS, Katharina S, Paul L, Lars T, Wilfried K, Mirko N, et al. Galectin-1 expression in human glioma cells: Modulation by ionizing radiation and effects on tumor cell proliferation and migration. Oncol Report 2007;18:483-8.****

12. Perillo NL, Marcus ME, Baum LG. Galectins: versatile modulators of cell adhesion, cell proliferation, and cell death. J Mol Med (Berl) 1998;76:402-12.

13. Camby I, Le Mercier M, Lefranc F, Kiss R. Galectin-1: a small protein with major functions. Glycobiology 2006;16:137R-57R.

14. Rizqiawan A, Tobiumei K, Okui G, Yamamoto K, Shigeishi H, Ono S, et al. Autocrine galectin-1 promotes collective cell migration of squamous cell carcinoma cells through up-regulation of distinct integrins. Biochem Biophys Res Commun 2013;441:904-10.

15. Kim HJ, Jeon HK, Cho YJ, Park YA, Choi JJ, Do IG, et al. High galectin-1 expression correlates with poor prognosis and is involved in epithelial ovarian cancer proliferation and invasion. Eur J Cancer 2012;48:1914-21.

16. Fischer C, Sanchez-Ruderisch H, Welzel M, Wiedenmann B, Sakai T, André S, et al. Galectin-1 interacts with the \{alpha $5\{$ beta $\} 1$ fibronectin receptor to restrict carcinoma cell growth via induction of p21 and p27. J Biol Chem 2005;280:37266-77.

17. Hossaka TA, Ribeiro DA, Focchi G, André S, Fernandes M, Lopes Carapeto FC, et al. Expression of galectins 1, 3 and 9 in normal oral epithelium, oral squamous papilloma, and oral squamous cell carcinoma. Dent Res j (Isfahan) 2014;11:508-12.

18. Noda Y, Kondo Y, Sakai M, Sato S, Kishino M. Galectin-1 is a useful marker for detecting neoplastic squamous cells in oral cytology smears. Hum Pathol 2016;52:101-9.

19. Noda Y, Kishino M, Sato S, Hirose K, Sakai M, Fukuda Y, et al. Galectin-1 expression is associated with tumour immunity and prognosis in gingival squamous cell carcinoma. J Clin Pathol 2017;70:126-33.

20. Wu HW, Tse MH, Hui WC. Galectin-1 mediated tumor invasion and metastasis, up-regulated matrix metalloproteinase expression, and reorganized actin cytoskeleton. Mol Cancer Res. 2009;7:311-318 